American Journal of Pharmaceutical Education 2020; 84 (11) Article 8173.

\title{
COMMENTARY
}

\section{Scholarship Does Not Have to Be Hard}

\author{
Timothy J. Bloom, $\mathrm{PhD}^{\mathrm{a}, \mathrm{b}}$ \\ a Shenandoah University, Bernard J. Dunn School of Pharmacy, Winchester, Virginia \\ ${ }^{\mathrm{b}}$ Editorial Board Member, American Journal of Pharmaceutical Education, Arlington, Virginia \\ Submitted May 18, 2020; accepted May 31, 2020; published November 2020.
}

Keywords: scholarship, faculty development

Scholarship is an important part of the academic environment. It is one of three main areas used to evaluate faculty members for promotion and tenure, but the idea of a scholarly mindset touches multiple elements of academic pharmacy for both faculty members and students. The Accreditation Council for Pharmacy Education (ACPE) Standards 2016 include an expectation of faculty scholarship, stating "The college or school creates an environment that both requires and promotes scholarship and also develops mechanisms to assess both the quantity and quality of faculty scholarly productivity."1 The 20112012 American Association of Colleges of Pharmacy's Academic Affairs Standing Committee report advocated a scholarly approach to teaching, defined as ".... [going] beyond content knowledge and preparing and delivering lecture content to include evidence-based practice and pedagogical knowledge of teaching and motivation best practices."2 The ACPE's Standards 2016 also support the importance of a scholarly mindset for students, stating they should be prepared for "Evaluation of research methods and protocol design required to conduct valid and reliable studies to test hypotheses or answer research questions, and to appropriately evaluate the validity and reliability of the conclusions of published research studies." "The Pharmacists Patient Care Process, widely endorsed and supported by professional pharmacy organizations, can be described as a scholarly approach to patient care, with data collection and assessment steps familiar to anyone experienced with experimental design. ${ }^{3}$

With this widespread emphasis on a scholarly approach, one might assume it is easy for pharmacy faculty members to be productive scholars, but maintaining a consistent scholarly output can be quite difficult. There are many reasons scholarly activity might slow over time.

Corresponding Author: Timothy J. Bloom, Shenandoah University, Bernard J. Dunn School of Pharmacy, 1775 N. Sector Ct., Winchester, VA 22601. Tel: 540-678-4395. Email: tbloom2@su.edu
Scholarly productivity can be difficult at a teaching-focused institution due to higher teaching loads or a culture that emphasizes being available to students. Science faculty members at these schools may have less access to the resources needed for bench science, and pharmacy practice faculty members may find it difficult to do research while maintaining a practice site. Changes in the industrial and governmental funding environments mean faculty members at any institution may struggle to get the funding needed to support cutting-edge research, while clinical faculty members can face pressure to bring in money through providing patient care. Faculty interests may change over time, and senior faculty members are often expected to contribute more to the governance of their department, school, or university. Those who started their careers excited by research may find it difficult to maintain their momentum as time passes.

When doing high-level research becomes difficult, many faculty members may be tempted to let it go. My own experiences as a faculty member reflect many of these challenges. At the state flagship university where I was a graduate student, the culture centered on research. The education and training I received aimed to prepare me for a tenure-track faculty position but focused largely on developing my research skills. In my first faculty role, I had a department chair interested in boosting the research environment at a teaching-focused school of pharmacy. His goals aligned with my training, so I spent time and energy getting students interested in working in the laboratory and going through multiple rounds of applying for extramural funding. I was fortunate enough to apply when National Institutes of Health funding was easier to get than it is now, and I managed to get some publications out of the funded research, though not of the caliber that I had completed in graduate school.

Gradually, I did less and less of the research my graduate training focused on. Some reasons for this decline were internal. Despite having a National Academy of Sciences member for a research advisor and a Nobel Prize winner on my dissertation committee, I never really 


\section{American Journal of Pharmaceutical Education 2020; 84 (11) Article 8173.}

picked up the mindset needed for a consistent research path. I was told that keeping focused on a single research question would build a history that would increase my funding chances, which would in turn support my continued research. In that world, this focus was a strength that would ensure success as a faculty member. But I had a problem with curiosity. Interesting results that did not seem to fit expectations created distracting rabbit holes that were hard for me to ignore. I was not able to quickly and efficiently finish the work I had proposed to a funder, making grant renewal requests difficult. There were also institutional barriers familiar to any bench scientist working at a teaching-focused university. Because of limited department resources, I was responsible for ordering my supplies and keeping up with business office reports on my budget. I even served as the university radiation safety officer because I was the primary user on campus. All of these administrative tasks made laboratory work more and more burdensome. There were other things I could more easily focus on, such as teaching and service. Both of these areas were easier for me to perform successfully, and were attractive because they earned me more respect from many of my colleagues. Thus, after more than a decade of faculty experience, my research efforts began to fall by the wayside.

In 2013-2014, being part of the tenth Academic Leaders Fellowship Program cohort gave me my first experience with educational research. It was often described differently, however, with people using the word scholarship rather than research. Scholarship, as I heard about it then, seemed to be something different from the research that had surrounded me in graduate school. Scholarship seemed to be more flexible and often focused around something of personal interest and curiosity rather than on one narrow question that was of interest to a funding agency. I learned I could be successful with scholarship by identifying an interesting topic, looking through the published literature for information on that topic, finding some aspect I did not see in the literature, addressing it, and then moving on to the next interesting thing. Finding rabbit holes was now a feature of my scholarship rather than a bug. Over the past six years, I have had more papers published than I had published in my first 15 years as a faculty member, but no two have been on the same specific topic. A question occurs to me, I explore the question and learn as much as I can about how to address it, and add my findings to the literature. Then another question pops up and the cycle starts over again.

Several years ago, one of my projects found that many pharmaceutical sciences departments at non-research-intensive schools of pharmacy showed no publications of any kind over the four years examined, perhaps in part because of the reasons discussed above. Fewer than $3 \%$ of the publications from the faculty members in all of the departments analyzed were in pharmacy education journals. If the faculty members in those departments had been encouraged to apply their research ability to areas different from the resource-intensive work of their doctoral training, how much innovative energy could have been channeled into constructive scholarship? How much more might we know about effective teaching approaches, such as how to teach and assess students' preparation to use a scholarly approach to practice?

I salute those who are able to pursue a focused research agenda, whether in teaching and learning, clinical applications, or foundational benchwork. We would not be where we are today without those efforts, and I am grateful to all of those individuals. I am just not someone who can use that approach to satisfy my intellectual curiosity. Being able to look into things only because I am curious rather than because of perceived pressure to chase the current hot funding topic in my field is liberating. This freedom has been invigorating and I have recaptured the intellectual excitement I had as a graduate student. Scholarship, as with many things, is much more satisfying when the motivation is intrinsic rather than extrinsic. Whether I am doing a literature search, developing a research design, executing a project or writing it up, I look forward to the work each time, and it gives me a break from my other tasks and responsibilities. I have relearned in the past few years that scholarship can be fun, something I had gradually forgotten during the first 15 years after leaving graduate school. I still have to identify questions that others may also find interesting, as sharing through publication is a critical part of scholarship, and I have been fortunate to have collaborators and mentors to guide me. But I do not need to fit into the model of choosing a single, focused research question that I stick with over time. By following my wide-ranging curiosity, I can meet my institution's requirements for scholarship while still being able to do the teaching and service that are also important to me.

\section{REFERENCES}

1. Accreditation Council for Pharmacy Education. Accreditation standards and key elements for the professional program in pharmacy leading to the doctor of pharmacy degree. https:/www.acpeaccredit.org/pdf/Standards2016FINAL.pdf. Accessed May 8, 2020. 2. Medina MS, Bouldin AS, Gonyeau M, et al. Report of the 20112012 Academic Affairs Standing Committee: the evolving role of scholarly teaching in teaching excellence for current and future faculty. Am J Pharm Educ. 2012;76(6):Article S5.

3. Joint Commission of Pharmacy Practitioners. The Pharmacists' Patient Care Process. https://jcpp.net/patient-care-process/. Accessed May 8, 2020. 